\title{
Combination Therapies with Thiazolidinediones are Associated with a Lower Risk of Acute Exacerbations in New-Onset COPD Patients with Advanced Diabetic Mellitus: A Nested Case- Control Study
}

\author{
Kuan-Yuan Chen \\ Taipei Medical University \\ Sheng-Ming Wu \\ Taipei Medical University \\ Chien-Hua Tseng \\ Taipei Medical University \\ Kang-Yun Lee \\ Taipei Medical University \\ Yu-Huei Lin \\ Taipei Medical University \\ Hung-Yi Liu \\ Taipei Medical University \\ Li-Nien Chien ( $\square$ Inchien@tmu.edu.tw ) \\ Taipei Medical University https://orcid.org/0000-0001-9441-552X
}

\section{Research article}

Keywords: oral antihyperglycemic drugs (OADs), thiazolidinediones (TZDs), type 2 diabetes mellitus (T2DM), acute exacerbation chronic obstructive pulmonary disease (AECOPD), nested case-control study

Posted Date: September 8th, 2020

DOI: https://doi.org/10.21203/rs.3.rs-62193/v1

License: (c) (i) This work is licensed under a Creative Commons Attribution 4.0 International License. Read Full License 


\section{Abstract}

BACKGROUND: The effects of oral antihyperglycemic drugs (OADs) for T2DM on outcomes of co-existing COPD patients have been less concerned. We examined the association of combinational OADs and risk of AECOPD in T2DM patients with co-existing COPD

METHODS: A nested case-control study was conducted using data from the National Health Insurance Research Database of Taiwan. Among new-onset COPD-T2DM patients, 65,370 were prescribed with metformin and $2^{\text {nd }}$ line OADs before the date of COPD onset. Each AECOPD case was matched to 4 randomly selected controls according to the propensity score estimated by patient's baseline characteristics. Conditional logistic regression analysis was performed to estimate the association between AECOPD risk and OADs use.

RESULTS: Among COPD-T2DM patients, 3,355 AECOPD cases and 13,420 matched controls were selected. All COPD-T2DM patients with a double combination of oral OADs $(n=12,916)$, AECOPD patients were less likely to be exposed to SU and thiazolidinediones (TZD) compared to the patients received metformin (MET) and sulfonylurea (SU), with an adjusted odds ratio (OR) of 0.69 (95\% confidence interval [Cl]: $0.51-0.94, P=0.02)$. Of the patients with a triple combination of oral OADs $(n=3,859)$, we found that MET, SU and TZD had a lower risk of AECOPD (adjusted OR=0.81 (0.68-0.96, $P=0.01$ ) compared to a combination of MET, SU and a-glucosidase inhibitors (AGI) regardless the level of COPD complexity.

CONCLUSION: Combination therapies with TZD were associated with reducing risk of AECOPD in advanced T2DM patients with co-existing COPD.

\section{Background}

Multiple comorbidities in type 2 diabetes mellitus (T2DM) are common, and there might be only $14 \%$ patients without other comorbidities (1). This would add complexity in choosing therapeutic drugs for glycemic control when considering impact of different classes of medication on comorbidities. Chronic obstructive pulmonary disease (COPD) is a common comorbidity in patients with T2DM; about $10 \%$ of T2DM patients coexisting with $\operatorname{COPD}(2,3)$. Recent studies have demonstrated that either preexisting or incident diabetes can worsen risk of mortality in COPD or acute examinations of COPD (AECOPD) patients $(4,5)$. Therefore, it is imperative to optimize DM care of the COPD population.

The recently updated guideline from American Diabetes Association (ADA) recommends metformin, if not contraindicated and if tolerated, is the preferred initial oral antihyperglycemic drug (OAD) for the treatment of T2DM (6). As the progressive natural course of T2DM, when metformin monotherapy is no longer effective, the majority of advanced T2DM patients require combination of different 2nd OADs or insulin therapy to achieve and maintain optimal glycemic control. ADA dose not prioritize specific 2nd drugs based on their efficacy, side effects and impact on comorbidities except for cardiovascular and renal effect (6).

In COPD-T2DM patients, it is uncertain whether tighter glucose control can improve COPD outcome, but poor sugar control worsen the severity and clinical course of COPD was reported in on year prospective study $(7,8)$. Though there were studies explored the influence of OADs on clinical outcomes of COPD such as metformin (MET) and thiozolidinediones (TZDs) (9-11), comparative little research focus on effect of glucose-lowing agents on COPD outcomes with T2DM patients, particularly in those with poorly glycemic control requiring add-on therapy to metformin. There is still a knowledge gap for selecting optimal drugs both beneficial to glycemic control and better clinical outcomes of new-onset COPD patients with advanced T2DM currently. Therefore, the aim of this study was to examine the effect of add-on OADs on AECOPD risk in new-onset COPD patients with advanced T2DM required combinational therapy. We conducted a nested case-control study by using data from the National Health Insurance Research Database (NHIRD) of Taiwan.

\section{Methods}

\section{Data Source}


The NHIRD, provided by the National Health Insurance Administration (NHIA) of Taiwan, is a nationwide claims-based database of the National Health Insurance (NHI) program. The NHI program, launched in 1995, is a compulsory insurance program that provides reimbursement for most medical services and over 30000 prescription drugs. The data used in the study were collected between 2000 and 2015 and were maintained by the Health and Welfare Data Science Center (HWDC), Ministry of Health and Welfare, Executive Yuan, Taiwan. The NHIRD files include inpatient, outpatient and drug prescription claims and use the International Classification of Diseases, Ninth Revision, Clinical Modification (ICD-9-CM) and the Anatomical Therapeutic Chemical (ATC) system to define the patients had a specific disease diagnosis or drug prescription. To verify the accuracy of the diagnoses and the rationale for treatments, the NHIA also routinely samples and reviews a proportion of NHI claims. In addition, hospitals and clinics are penalized if they provide any unnecessary medical treatment to patients. Besides, each patient has a unique encrypted identifier which can be linked to National Death Registry under the regulation of HWDC. This study was approved by the Joint Institutional Review Board of Taipei Medical University (approval no. N201808075).

\section{Study Cohort}

The initial cohort consisted of new-onset COPD patients with diabetes between 2003 and 2014. COPD patients were defined if the patients had at least three disease diagnostic claims within a year of follow-up and at least a three-year washout period was adopted to ensure the patients were newly diagnosed with COPD. We then excluded the patients had unknown sex, were not a citizen in Taiwan, or were aged less than 40-year old (1); had no COPD prescription claim within a year after the first date of COPD diagnosis (2); had a disease history of asthma, malignant tumor, chronic kidney disease, and renal dialysis (3); had a diagnosis of type 1 diabetes or had no antidiabetic drug prescription claim or had metformin monotherapy and had insulin therapy before the first COPD diagnosis (4). The later exclusion was made to increase the homogeneity of the study cohort.

\section{Case and Control Patient Selection}

There is no general agreement on definition of AECOPD. Mostly, the definition of AECOPD was based on increasing symptoms and/or increased health care utilization. Thus, in this claim-based study, we used the following approach to identify the patients with AECOPD modified according to previous study $(12,13)$ if they 1$)$ had a hospital admission or an emergency visit due to COPD and also requiring oral or injection corticosteroid (CS), or 2) added on oral or injection CS therapy in a new visit. To increase the comparability, matched controls were selected based on incidence density sampling which involved in matching each AECOPD case to a sample of those potential controls who were at risk at the time of case occurrence, resulting obtaining unbiased estimates of relative risk. Before matching, we additionally excluded the patients had monotherapy and then included subjects with double or triple combination therapy of OADs which regimen were validated by clinical trials and meta-analyses (14). Finally, each case was matched to 4 randomly selected controls according to the propensity score estimation by sex, age, the year of COPD diagnosis, the initial year of DM status, previous and coexisting disease conditions, Charlson comorbidity index (CCI), level complexity of COPD and the COPD medication use three month prior to the date of AECOPD. The initial year of DM status was defined based on the first claim year of the patients initially received 2 nd line OADs continuously for at least three month. Since control patients did not occurred AECOPD, they were assigned a date for pseudo-AECOPD which corresponded to the index date of their matched cases.

\section{Exposure to oral antihyperglycemic drugs (OADs)}

We examined all OAD prescription records within three month before the index date of AECOPD of cases and pseudo-AECOPD date of controls, respectively. We investigated the type of OADs, including metformin (MET), sulfonyurea (SU), a-glucosidase inhibitors (AGI), thiazolidinediones (TZD) and dipeptidyl peptidase-4 inhibitor (DPP-4i). The aim of our study is to answer what is the best drug as add-on OADs to monotherapy for progressive T2DM in the context of considering effect on COPD outcomes. Then, we further categorized T2DM-COPD patients by using a double or triple combination of OADs.

\section{Potential Confounding Variables}


Previous or coexisting medical conditions were recorded if patients were diagnosed with chronic artery disease (CAD), hypertension (HTN), congestive heart failure (CHF), pneumonia, chronic liver disease (CLD), dementia/Parkinson and osteoporosis. Additionally, $\mathrm{CCl}$ which is represented the severity of comorbid conditions of patients was also considered a major risk and the $\mathrm{CCl}$ in this current study has been modified since all patients had diagnosed with both diabetes and COPD but did not have a history of malignant neoplasm. To adjust the severity of COPD itself, we categorized patients into low, moderate and high complexity according to the previous study (15) and further grouped the patients into low and moderate/high complexity group due to a small sample size of high complexity. Besides, we also considered the history of COPD medication use of AECOPD cases and non-AECOPD controls, respectively (15), including short acting beta agonists (SABA), short-acting muscarinic antagonists (SAMA), long-acting beta agonists (LABAs), long-acting muscarinic antagonists (LAMAs) and inhaled corticosteroids (ICS).

\section{Statistical Analysis}

The baseline differences between case and control patients were measured by standardized mean difference (SMD). Conditional logistic regression was used to estimate the odd ratios (OR), adjusted odds ratios (aOR), and 95\% confidence intervals (CI) for the association of AECOPD risk and OADs use. The statistical analyses were performed using SAS/STAT, Version 9.4, (SAS Institute, Cary, NC, USA) and STATA 13 (Stata Corp, College Station, TX, USA). A $P$ value $<0.05$ and SMD $>0.1$ was set as the level of statistical significance.

\section{Results}

\section{Baseline Characteristics}

Of new-onset COPD patients with advanced T2DM, 3,355 AECOPD cases and 13,420 non-AECOPD matched controls were selected by using an incidence density sampling method (Fig. 1). The baseline characteristics of the case and control patients are shown in Table 1. In COPD-T2DM cohort, two-third of AECOPD cases were male and the mean age was 72 years old (SD: 10.5). The 3 most common previous or coexisting disease conditions were hypertension (65.0\%), CAD (20.8\%) and pneumonia (12.9\%) and $42.1 \%$ had a modified CCl between 1 and 2 . In terms of the level of COPD complexity at initial diagnosis, around half and half patients were classified into a low-level and moderate/high-level, respectively. For COPD medication three months before the index date of AECOPD, majority of patients had received ICS or steroid and only $3 \%$ of the patients received either SABA, SAMA, LABA or LAMA. Since we used the propensity score approach to adjust the baseline characteristics of AECOPD cases and non-AECOPD controls, the groups were not different in the variables listed in Table 1. 
Table 1

Baseline difference between AECOPD case patients and non-AECOPD control T2DM patients

\begin{tabular}{|c|c|c|c|c|c|}
\hline \multirow[t]{2}{*}{ Variables } & \multicolumn{2}{|c|}{ Non-AECOPD controls } & \multicolumn{2}{|c|}{ AECOPD cases } & \multirow[t]{2}{*}{ SMD } \\
\hline & $\mathrm{n}$ & (\%) & $\mathrm{n}$ & (\%) & \\
\hline Sample size & 13,420 & & 3,355 & & \\
\hline Male, yes & 8,956 & $(66.7)$ & 2,239 & $(66.7)$ & 0.000 \\
\hline Age, [mean, SD] & {$[72.2,1$} & & {$[72.1]$,} & & \\
\hline $40-49$ & 350 & $(2.6)$ & 92 & $(2.7)$ & 0.008 \\
\hline $50-59$ & 1,437 & $(10.7)$ & 357 & $(10.6)$ & 0.002 \\
\hline $60-69$ & 2,902 & $(21.6)$ & 759 & $(22.6)$ & 0.024 \\
\hline $70-79$ & 5,318 & $(39.6)$ & 1,266 & (37.7) & 0.039 \\
\hline$>=80$ & 3,413 & $(25.4)$ & 881 & $(26.3)$ & 0.019 \\
\hline \multicolumn{6}{|c|}{ Year of the first DM claim } \\
\hline $2000 \sim 2002$ & 8,059 & $(60.1)$ & 2,035 & $(60.7)$ & 0.012 \\
\hline $2003 \sim 2006$ & 3,114 & $(23.2)$ & 769 & $(22.9)$ & 0.007 \\
\hline $2007 \sim 2010$ & 1,681 & $(12.5)$ & 418 & $(12.5)$ & 0.002 \\
\hline $2011 \sim 2014$ & 566 & $(4.2)$ & 133 & $(4.0)$ & 0.013 \\
\hline \multicolumn{6}{|c|}{ Year of COPD diagnosis } \\
\hline $2003 \sim 2006$ & 4,411 & (32.9) & 1,121 & (33.4) & 0.012 \\
\hline $2007 \sim 2010$ & 4,906 & $(36.6)$ & 1,228 & $(36.6)$ & 0.001 \\
\hline $2011 \sim 2014$ & 4,103 & $(30.6)$ & 1,006 & $(30.0)$ & 0.013 \\
\hline \multicolumn{6}{|c|}{ Previous or coexisting disease conditions, yes } \\
\hline HTN & 8,671 & $(64.6)$ & 2,182 & $(65.0)$ & 0.009 \\
\hline CAD & 2,867 & $(21.4)$ & 698 & $(20.8)$ & 0.014 \\
\hline CHF & 1,109 & (8.3) & 282 & (8.4) & 0.005 \\
\hline AF & 581 & $(4.3)$ & 154 & $(4.6)$ & 0.013 \\
\hline Pneumonia & 1,761 & $(13.1)$ & 433 & $(12.9)$ & 0.006 \\
\hline CLD & 849 & (6.3) & 216 & $(6.4)$ & 0.005 \\
\hline Dementia/Parkinson & 1,425 & $(10.6)$ & 364 & (10.8) & 0.007 \\
\hline Osteoporosis & 447 & (3.3) & 114 & (3.4) & 0.004 \\
\hline CCI, [mean, SD] & {$[1.5,1.5$} & & {$[1.6,1$. } & & \\
\hline 0 & 4,294 & (32.0) & 1,078 & (32.1) & 0.003 \\
\hline
\end{tabular}

*SMD = difference in means or proportions divided by standard error; imbalance defined as absolute value greater than 0.1

Abbreviation: AECOPD, acute exacerbations chronic obstructive pulmonary disease; $\mathrm{CAD}$, coronary artery disease; $\mathrm{CCl}$, Charlson comorbidity index; CHF, congestive heart failure; CLD, chronic liver disease; COPD, chronic obstructive pulmonary disease; DM, diabetes mellitus; HTN, hypertension; SMD, standardized mean difference; SABA, short-acting beta agonists; SAMA, short-acting muscarinic antagonist; LABA, long-acting beta agonists; LAMA, long-acting muscarinic antagonist; ICS, Inhaled corticosteroids 


\begin{tabular}{|c|c|c|c|c|c|}
\hline \multirow[t]{2}{*}{ Variables } & \multicolumn{2}{|c|}{ Non-AECOPD controls } & \multicolumn{2}{|c|}{ AECOPD cases } & \multirow[t]{2}{*}{ SMD } \\
\hline & $\mathbf{n}$ & (\%) & $\mathbf{n}$ & (\%) & \\
\hline $1 \sim 2$ & 5,893 & $(43.9)$ & 1,412 & $(42.1)$ & 0.037 \\
\hline$>=3$ & 3,233 & $(24.1)$ & 865 & $(25.8)$ & 0.039 \\
\hline \multicolumn{6}{|c|}{ Level of COPD complexity at initial diagnosis } \\
\hline Low & 6,689 & $(49.8)$ & 1,722 & $(51.3)$ & 0.030 \\
\hline Moderate/high & 6,731 & $(50.2)$ & 1,633 & $(48.7)$ & 0.030 \\
\hline \multicolumn{6}{|c|}{ COPD medication use 3 month prior to index date, yes } \\
\hline SABA or SAMA & 169 & $(1.3)$ & 39 & $(1.2)$ & 0.009 \\
\hline LABA or LAMA & 417 & (3.1) & 60 & (1.8) & 0.085 \\
\hline ICS or Steroid & 12,682 & $(94.5)$ & 3,210 & (95.7) & 0.054 \\
\hline Others & 152 & (1.1) & 46 & $(1.4)$ & 0.021 \\
\hline \multicolumn{6}{|c|}{ *SMD = difference in means or proportions divided by standard error; imbalance defined as absolute value greater than 0.1} \\
\hline \multicolumn{6}{|c|}{$\begin{array}{l}\text { Abbreviation: AECOPD, acute exacerbations chronic obstructive pulmonary disease; CAD, coronary artery disease; } C C I \text {, } \\
\text { Charlson comorbidity index; CHF, congestive heart failure; CLD, chronic liver disease; COPD, chronic obstructive pulmonary } \\
\text { disease; DM, diabetes mellitus; HTN, hypertension; SMD, standardized mean difference; SABA, short-acting beta agonists; } \\
\text { SAMA, short-acting muscarinic antagonist; LABA, long-acting beta agonists; LAMA, long-acting muscarinic antagonist; ICS, } \\
\text { Inhaled corticosteroids }\end{array}$} \\
\hline
\end{tabular}


Table 2

The association between double oral OADs use and risk of AECOPD in T2DM patients with COPD $(n=12,916)$

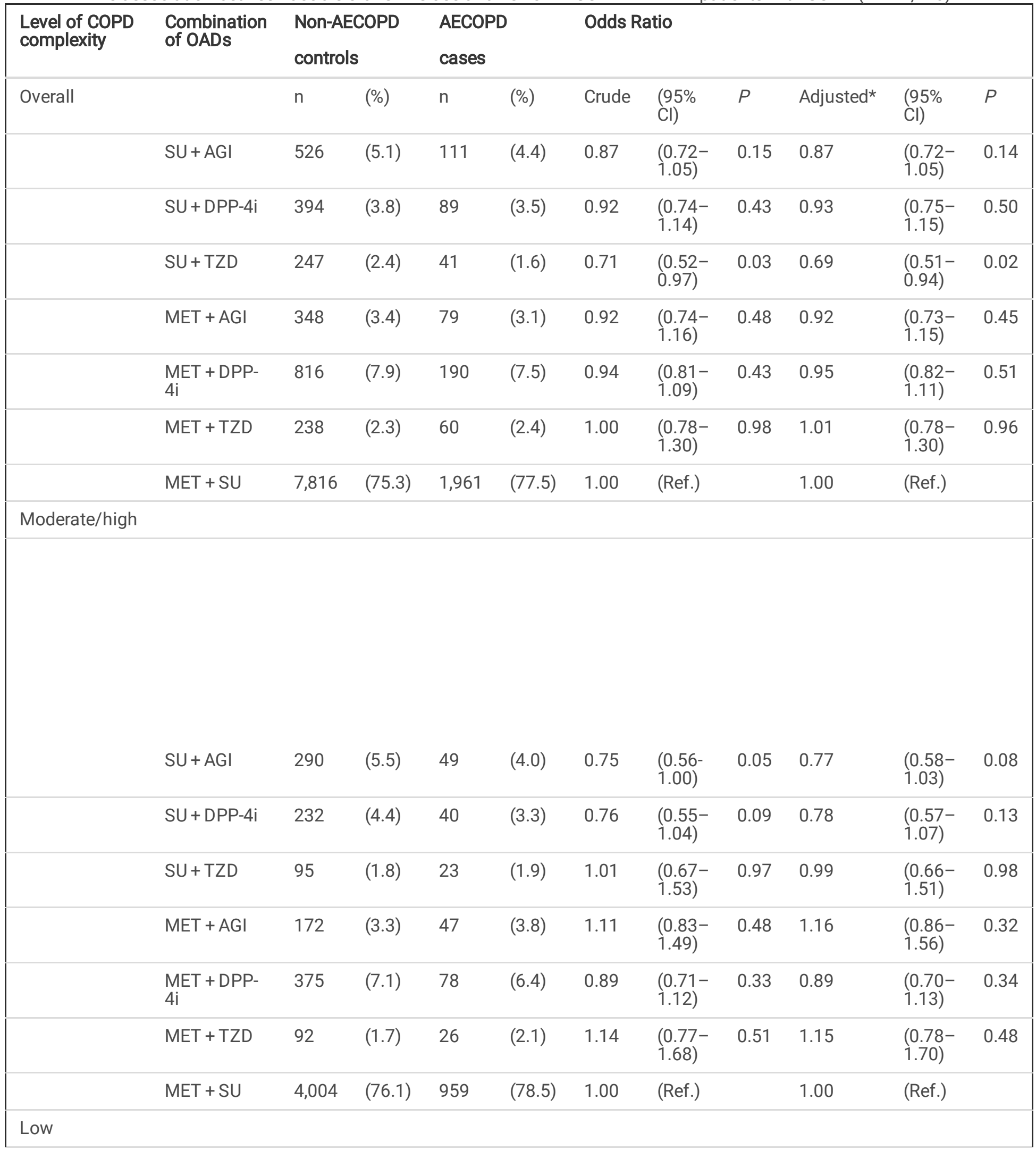

*Adjusted for age, sex, DM status, previous and coexisting disease conditions, modified CCI, complexity of COPD and COPD medications listed in Table 1

Abbreviation: AECOPD, acute exacerbations chronic obstructive pulmonary disease; AGI: a-glucosidase inhibitors; $\mathrm{CCl}$, Charlson comorbidity index; Cl, confidence interval; DPP-4i, dipeptidyl peptidase-4 inhibitor; DM, diabetes; MET, metformin; OADs, oral antihyperglycemic drugs; OR, odd ratio; Ref., reference group; SU, sulfonylurea; TZD, thiazolidinediones 


\begin{tabular}{|c|c|c|c|c|c|c|c|c|c|c|c|}
\hline \multirow[t]{2}{*}{$\begin{array}{l}\text { Level of COPD } \\
\text { complexity }\end{array}$} & \multirow{2}{*}{$\begin{array}{l}\text { Combination } \\
\text { of OADs }\end{array}$} & \multicolumn{2}{|c|}{$\begin{array}{l}\text { Non-AECOPD } \\
\text { controls }\end{array}$} & \multicolumn{2}{|c|}{$\begin{array}{l}\text { AECOPD } \\
\text { cases }\end{array}$} & \multicolumn{6}{|c|}{ Odds Ratio } \\
\hline & & 236 & $(4.6)$ & 62 & $(4.7)$ & 1.00 & $\begin{array}{l}(0.77- \\
1.29)\end{array}$ & 1.00 & 0.96 & $\begin{array}{l}(0.74- \\
1.24)\end{array}$ & 0.76 \\
\hline & SU + DPP-4i & 162 & (3.2) & 49 & (3.7) & 1.12 & $\begin{array}{l}(0.84- \\
1.49)\end{array}$ & 0.45 & 1.11 & $\begin{array}{l}(0.83- \\
1.47)\end{array}$ & 0.49 \\
\hline & SU + TZD & 152 & (3.0) & 18 & $(1.4)$ & 0.51 & $\begin{array}{l}(0.32- \\
0.81)\end{array}$ & $\begin{array}{l}< \\
0.01\end{array}$ & 0.50 & $\begin{array}{l}(0.32- \\
0.80)\end{array}$ & $\begin{array}{l}< \\
0.01\end{array}$ \\
\hline & $\mathrm{MET}+\mathrm{AGI}$ & 176 & (3.4) & 32 & $(2.4)$ & 0.74 & $\begin{array}{l}(0.52- \\
1.05)\end{array}$ & 0.09 & 0.74 & $\begin{array}{l}(0.52- \\
1.05)\end{array}$ & 0.10 \\
\hline & $\begin{array}{l}\text { MET + DPP- } \\
4 \mathrm{i}\end{array}$ & 441 & (8.6) & 112 & $(8.6)$ & 0.97 & $\begin{array}{l}(0.80- \\
1.18)\end{array}$ & 0.78 & 0.99 & $\begin{array}{l}(0.81- \\
1.21)\end{array}$ & 0.90 \\
\hline & MET + TZD & 146 & $(2.8)$ & 34 & (2.6) & 0.91 & $\begin{array}{l}(0.64- \\
1.28)\end{array}$ & 0.58 & 0.93 & $\begin{array}{l}(0.66- \\
1.32)\end{array}$ & 0.70 \\
\hline & $\mathrm{MET}+\mathrm{SU}$ & 3,812 & $(74.4)$ & 1,002 & $(76.5)$ & 1.00 & (Ref.) & & 1.00 & (Ref.) & \\
\hline \multicolumn{12}{|c|}{$\begin{array}{l}\text { *Adjusted for age, sex, DM status, previous and coexisting disease conditions, modified CCl, complexity of COPD and COPD } \\
\text { medications listed in Table } 1\end{array}$} \\
\hline \multicolumn{12}{|c|}{$\begin{array}{l}\text { Abbreviation: AECOPD, acute exacerbations chronic obstructive pulmonary disease; AGI: a-glucosidase inhibitors; } \mathrm{CCl} \text {, } \\
\text { Charlson comorbidity index; CI, confidence interval; DPP-4i, dipeptidyl peptidase-4 inhibitor; DM, diabetes; MET, metformin; } \\
\text { OADs, oral antihyperglycemic drugs; OR, odd ratio; Ref., reference group; SU, sulfonylurea; TZD, thiazolidinediones }\end{array}$} \\
\hline
\end{tabular}


Table 3

The association between triple oral OADs use and risk of AECOPD in T2DM patients with COPD $(n=3,859)$

\begin{tabular}{|c|c|c|c|c|c|c|c|c|c|c|c|}
\hline \multirow{2}{*}{$\begin{array}{l}\text { Level of COPD } \\
\text { complexity } \\
\text { Overall }\end{array}$} & \multirow[t]{2}{*}{$\begin{array}{l}\text { Combination } \\
\text { of OADs }\end{array}$} & \multicolumn{2}{|c|}{$\begin{array}{l}\text { Non-AECOPD } \\
\text { controls }\end{array}$} & \multicolumn{2}{|c|}{$\begin{array}{l}\text { AECOPD } \\
\text { cases }\end{array}$} & \multicolumn{6}{|c|}{ Odds Ratio } \\
\hline & & $\mathrm{n}$ & (\%) & $n$ & (\%) & Crude & $\begin{array}{l}(95 \% \\
\mathrm{Cl})\end{array}$ & $P$ & Adjusted* & $\begin{array}{l}(95 \% \\
\mathrm{Cl})\end{array}$ & $P$ \\
\hline & $\begin{array}{l}\text { MET + SU + } \\
\text { TZD }\end{array}$ & 1,074 & $(35.4)$ & 243 & $(29.5)$ & 0.81 & $\begin{array}{l}(0.68- \\
0.95)\end{array}$ & 0.01 & 0.81 & $\begin{array}{l}(0.68- \\
0.96)\end{array}$ & 0.01 \\
\hline & $\begin{array}{l}\text { MET + SU + } \\
\text { DPP-4i }\end{array}$ & 933 & $(30.7)$ & 276 & (33.5) & 1.00 & $\begin{array}{l}(0.85- \\
1.17)\end{array}$ & 0.98 & 1.02 & $\begin{array}{l}(0.87- \\
1.21)\end{array}$ & 0.78 \\
\hline & $\begin{array}{l}\mathrm{MET}+\mathrm{SU}+ \\
\mathrm{AGI}\end{array}$ & 1,028 & (33.9) & 305 & $(37.0)$ & 1.00 & (Ref.) & & 1.00 & (Ref.) & \\
\hline \multicolumn{12}{|l|}{ Moderate/high } \\
\hline & $\begin{array}{l}\text { MET + SU + } \\
\text { TZD }\end{array}$ & 479 & $(32.6)$ & 104 & $(25.3)$ & 0.76 & $\begin{array}{l}(0.60- \\
0.97)\end{array}$ & 0.03 & 0.75 & $\begin{array}{l}(0.58- \\
0.96)\end{array}$ & 0.02 \\
\hline & $\begin{array}{l}\text { MET + SU + } \\
\text { DPP-4i }\end{array}$ & 440 & $(29.9)$ & 138 & $(33.6)$ & 1.02 & $\begin{array}{l}(0.81- \\
1.28)\end{array}$ & 0.87 & 1.06 & $\begin{array}{l}(0.84- \\
1.34)\end{array}$ & 0.63 \\
\hline & $\begin{array}{l}\mathrm{MET}+\mathrm{SU}+ \\
\mathrm{AGI}\end{array}$ & 552 & $(37.5)$ & 169 & $(41.1)$ & 1.00 & (Ref.) & & 1.00 & (Ref.) & \\
\hline \multicolumn{12}{|l|}{ Low } \\
\hline & $\begin{array}{l}\text { MET + SU + } \\
\text { TZD }\end{array}$ & 595 & $(38.0)$ & 139 & (33.7) & 0.85 & $\begin{array}{l}(0.67- \\
1.08)\end{array}$ & 0.18 & 0.88 & $\begin{array}{l}(0.79- \\
1.28)\end{array}$ & 0.28 \\
\hline & $\begin{array}{l}\mathrm{MET}+\mathrm{SU}+ \\
\text { DPP-4i }\end{array}$ & 493 & $(31.5)$ & 138 & (33.4) & 0.98 & $\begin{array}{l}(0.78- \\
1.25)\end{array}$ & 0.89 & 1.00 & $\begin{array}{l}(0.69- \\
1.11)\end{array}$ & 0.97 \\
\hline & $\begin{array}{l}\mathrm{MET}+\mathrm{SU}+ \\
\mathrm{AGI}\end{array}$ & 476 & $(30.4)$ & 136 & (32.9) & 1.00 & (Ref.) & & 1.00 & (Ref.) & \\
\hline \multicolumn{12}{|c|}{$\begin{array}{l}\text { *Adjusted for age, sex, DM status, previous and coexisting disease conditions, modified CCI, complexity of COPD and COPD } \\
\text { medications listed in Table } 1\end{array}$} \\
\hline \multicolumn{12}{|c|}{$\begin{array}{l}\text { Abbreviation: AECOPD, acute exacerbations chronic obstructive pulmonary disease; AGI: a-glucosidase inhibitors; } \mathrm{CCl} \\
\text { Charlson comorbidity index; Cl, confidence interval; DPP-4i, dipeptidyl peptidase-4 inhibitor; DM, diabetes; MET, metformin; } \\
\text { OADs, oral antihyperglycemic drugs; OR, odd ratio; Ref., reference group; SU, sulfonylurea; TZD, thiazolidinediones }\end{array}$} \\
\hline
\end{tabular}

\section{OADs Use and the Risk of AECOPD}

Among COPD-T2DM with double combination of oral OADs $(n=12,916)$, compared to patients who had received both MET and SU, AECOPD case patients were less likely to be exposed to a combination of SU and TZD within three months before the date of AECOPD compared to matched controls, with an adjusted odds ratio (OR) of 0.69 (95\% confidence interval [Cl]: $0.51-0.94, P=$ 0.02). When further divided the patients into low and moderate/high level of COPD complexity at the initial COPD diagnosis, we still found that the OADs use of a combination of SU and TZD was associated with a reduced risk of AECOPD of the patients with lower COPD complexity (adjusted $\mathrm{OR}=0.20,95 \% \mathrm{Cl}$ of $0.32-0.80$ ).

For the patients with a combination of triple OADs $(n=3,859)$, compared to the patients had MET, SU and Al, we found that AECOPD patients were less likely to have MET, SU and TZD, with an adjusted OR of 0.81 (95\% Cl: $0.68-0.96, P=0.01)$. Similar results were found in different level of COPD complexity; however, the finding was significant of the patients with a moderate/high level.

\section{Discussion}


Our study presented that COPD-T2DM patients use OADs only for sugar control, a double combination of SU and TZDs and a triple combination of MET, SU, and TZDs were associated with an decreased risk of AECOPD. The results were fairly consistent in patients with moderate or high complexity of COPD.

We found add-on TZDs could reduce risk of AECOPD in the double as well as the triple combination of OADs in COPD-T2DM cohorts. The result was in parallel with previous study which demonstrated TZDs are associated with a reduced risk of AECOPD after adjusting severity of DM per se with possible impact on AECOPD (11). In our study, we further considered the effect of COPD severity itself on AECOPD by using COPD complexity classification. We also took into account for the impact of medications use for COPD on AECOPD and founded the similar effect of TZD on decreasing frequency of AECOPD after adjusting these confounders.

COPD-T2DM are considered syndromes that can share risk factors (such as smoking) (16), genes (such as $\beta 2$-adrenergic receptor gene, ADRB2) (17), proteins (such as Nod-like receptor containing a pyrin domain 3 , NLRP3) $(18,19)$ and pathways (such as systemic inflammation and oxidative stress) (20-22). Although the underlying mechanistic links between these shared components are complex and not fully clarified, targeting systemic inflammation, an important common pathway to treat COPD and T2DM concurrently would be a rationale therapeutic approach (23).

Some OADs might have anti-inflammatory activity due to their pleiotropic effects in addition to reduce blood glucose $(24,25)$. TZDs, a class of OADs, have been studied with anti-inflammatory activity and introduced in the treatment of T2DM, mostly use in combination with metformin since the late 1990s (26). The cellular mechanisms of anti-inflammatory effects of TZD are through activating the nuclear transcription factor of peroxisome proliferator-activated receptor gamma (PPAR- $\gamma$ ) and at least in part, of glucocorticoid nuclear translocation $(27,28)$. Frequent AECOPD patients have more inflamed existing airway and systemic inflammation during exacerbations and even in the recovery period due to poor response of inflammation resolution from each episode (29-33). Therefore, TZDs may exert anti-inflammatory effect and downregulating the pro-inflammatory status for preventing from AECOPD. Besides, major comorbidities of COPD-T2DM such as cardiovascular diseases (CVDs) may induce or worsen AECOPD (34). Activating PPAR- $\gamma$ by TZDs also exert important function in regulating vascular inflammation and inhibiting vascular smooth muscle proliferation with effect against atherosclerosis (35-37). The protective role of TZDs on cardiovascular outcomes, particular in cumulative evidence from pioglitazone, may contribute to reduce CVDs-related AECOPD $(38,39)$.

There were two studies reported that metformin use had lower health care utilization and mitigated the adverse prognostic effect in COPD-T2DM patients $(9,10)$. However, no significant benefit effect of combination therapy with metformin use in our research. The major causes of the different results were attributed to the enrolled and analyzed patients. The favorable effect of metformin on reducing COPD-specific health care utilization only presented in lower complexity of COPD patients but not moderate to high complexities and the study did not showed the effect from mono- or combinational therapy with metformin. In our study, we clearly defined the combinational therapy with metformin and the data demonstrated no effect on reducing the risk of AECOPD in all COPD complexities. Furthermore, the other study presented COPD-T2DM patients get survival benefits of metformin but the effect may be confounded with the severity of COPD and the medications regimen for COPD. So the strength of our study is providing treatment suggestion that TZDs are better choice for combinational therapy whenever deterioration of glycemic control from initial control in COPD-T2DM patients. This recommendation was based on more strictly defined patient population, controlled of important clinical confounders and considered the impact of OADs on AECOPD. However, there were some limitations in the study. First, the data on drug exposure were acquired from prescription records, which might not reflect actual use. Second, the NHIRD lacks patient's other important information such as tobacco use, some vaccination administrated, medication compliance, which might contribute to AECOPD occurrence. Third, the administrative claims database from which the NHIRD sample was derived did not consider certain clinical characteristics, such as the severity of COPD. Although we applied the cross-sectional analysis developed by Mapel et al. (15) to adjust the potential effect of level of COPD severity on AECOPD risk, there was still some uncontrolled effects which might affect the finding in the study. Finally, this study included a cohort of Taiwanese patients, therefore, may not be generalizable to other populations due to variations of genetic and treatment guidelines for both diseases in other areas. Future prospective studies on the effects of TZDs are warranted to confirm our findings.

\section{Conclusion}


These results showed combination therapy with TZDs are associated with reducing risk of AECOPD regardless of double or triple combinational regimens in COPD-T2DM patients, particular in moderate to severe complexity COPD populations. It is believed the T2DM patients with co-existing COPD increase in the future, TZDs play different protection role for both diseases and suggested use in these patients but prospective randomized controlled trial are need to proof the results.

\section{Abbreviations}

COPD, Chronic obstructive pulmonary disease; OADs, oral antihyperglycemic drugs; TZDs, thiazolidinediones; CCI, Charlson comorbidity index; DPP-4i, dipeptidyl peptidase-4 inhibitor; T2DM, type 2 diabetes mellitus; AECOPD, acute exacerbation chronic obstructive pulmonary disease; MET, metformin; SU, sulfonylurea; OR, odds ratio; aOR, adjusted odds ratios; $\mathrm{Cl}$, confidence interval; AGI, a-glucosidase inhibitors; CAD, chronic artery disease; HTN, hypertension; CHF, congestive heart failure; CLD, chronic liver disease; SABA, short-acting beta-agonists; SAMA, short-acting muscarinic antagonists; LABAs, long-acting beta-agonists; LAMAs, long-acting muscarinic antagonists; ICS, inhaled corticosteroids; NLRP3, Nod-like receptor containing a pyrin domain; PPAR-y, peroxisome proliferator-activated receptor gamma.

\section{Declarations}

\section{Ethics approval and consent to participate}

The study protocol was approved by the Taipei Medical University-Joint Institutional Review Board (TMU-JIRB N201808075). All analyzes were performed in accordance with the relevant guidelines and regulations. Since all data were anonymously used, the TMU-IRB ethics committee approved a waiver of the requirement for informed consent. Individual patients consent was not obtained since all data used in this study were acquired retrospectively from the National Health Insurance Research Database of Taiwan.

\section{Consent for publication}

Not Applicable.

\section{Availability of data and materials}

The dataset used and/or analyzed during the current study are available from the corresponding author on reasonable request.

\section{Competing interests}

The authors declare no conflicts of interest or competing financial interests

\section{Funding}

This work was supported by grants from the Ministry of Science and Technology of the Republic of China (MOST 108-2314-B038-111-MY3; MOST 108-2314-B-038-063-MY3), Ministry of Education of the Republic of China (DP2-108-21121-01-T-04-01 and DP2-109-21121-01-T-01), Taipei Medical University and Shuang Ho Hospital (108TMU-SHH-02 and 108TMU-SHH-08) and Taipei Medical University (TMU107-AE1-B04).

\section{Author contributions}

K.Y.C. designed the research and wrote the manuscript. S.M.W. and C.H.T. supervised the analyses of statistics and patient information and reviewed the manuscript. Y.H.L and H.Y.L performed the analysis of statistics and patient information. K.Y.L. and L.N.C. supervised and reviewed the entire project and the manuscript. All authors contributed to data analysis, drafting or revising the article, gave final approval of the version to be published, and agree to be accountable for all aspects of the work.

\section{Acknowledgements}

Not Applicable. 


\section{References}

1. Suh DC, Choi IS, Plauschinat C, Kwon J, Baron M. Impact of comorbid conditions and race/ethnicity on glycemic control among the US population with type 2 diabetes, 1988-1994 to 1999-2004. J Diabetes Complications. 2010;24(6):382-91.

2. Caughey GE, Roughead EE, Vitry Al, McDermott RA, Shakib S, Gilbert AL. Comorbidity in the elderly with diabetes: Identification of areas of potential treatment conflicts. Diabetes Res Clin Pract. 2010;87(3):385-93.

3. Kerr EA, Heisler M, Krein SL, Kabeto M, Langa KM, Weir D, et al. Beyond comorbidity counts: how do comorbidity type and severity influence diabetes patients' treatment priorities and self-management? J Gen Intern Med. 2007;22(12):1635-40.

4. Ho TW, Huang CT, Ruan SY, Tsai YJ, Lai F, Yu CJ. Diabetes mellitus in patients with chronic obstructive pulmonary diseaseThe impact on mortality. PLoS One. 2017;12(4):e0175794.

5. Parappil A, Depczynski B, Collett P, Marks GB. Effect of comorbid diabetes on length of stay and risk of death in patients admitted with acute exacerbations of COPD. Respirology. 2010;15(6):918-22.

6. Association.8. AD. Pharmacologic Approaches to Glycemic Treatment. Diabetes Care. 2018;41(Supplement 1):S73-S85.

7. Chatila WM, Thomashow BM, Minai OA, Criner GJ, Make BJ. Comorbidities in chronic obstructive pulmonary disease. Proc Am Thorac Soc. 2008;5(4):549-55.

8. Mahishale V EA, Patil B, Lolly M and Khan S. Impact of Poor Glycemic Control on Severity and Clinical Course of Chronic Obstructive Pulmonary Disease in Patients With Co Existing Type 2 Diabetes Mellitus - One Year Prospective Study. SM J Pulm Med. 2015;1(2):1009.

9. Bishwakarma R, Zhang W, Lin YL, Kuo YF, Cardenas VJ, Sharma G. Metformin use and health care utilization in patients with coexisting chronic obstructive pulmonary disease and diabetes mellitus. Int J Chron Obstruct Pulmon Dis. 2018;13:793-800.

10. Ho TW, Huang CT, Tsai YJ, Lien AS, Lai F, Yu CJ. Metformin use mitigates the adverse prognostic effect of diabetes mellitus in chronic obstructive pulmonary disease. Respir Res. 2019;20(1):69.

11. Rinne ST, Liu CF, Feemster LC, Collins BF, Bryson CL, O'Riordan TG, et al. Thiazolidinediones are associated with a reduced risk of COPD exacerbations. Int J Chron Obstruct Pulmon Dis. 2015;10:1591-7.

12. Paggiaro PL, Dahle R, Bakran I, Frith L, Hollingworth K, Efthimiou J. Multicentre randomised placebo-controlled trial of inhaled fluticasone propionate in patients with chronic obstructive pulmonary disease. International COPD Study Group. Lancet. 1998;351(9105):773-80.

13. Burge PS, Calverley PM, Jones PW, Spencer S, Anderson JA, Maslen TK. Randomised, double blind, placebo controlled study of fluticasone propionate in patients with moderate to severe chronic obstructive pulmonary disease: the ISOLDE trial. BMJ. 2000;320(7245):1297-303.

14. Moon MK, Hur KY, Ko SH, Park SO, Lee BW, Kim JH, et al. Combination therapy of oral hypoglycemic agents in patients with type 2 diabetes mellitus. Korean J Intern Med. 2017;32(6):974-83.

15. Mapel DW, Dutro MP, Marton JP, Woodruff K, Make B. Identifying and characterizing COPD patients in US managed care. A retrospective, cross-sectional analysis of administrative claims data. BMC Health Serv Res. 2011;11:43.

16. Oh JY, Sin DD. Lung inflammation in COPD: why does it matter? F1000 Med Rep. 2012;4:23.

17. Grosdidier S, Ferrer A, Faner R, Pinero J, Roca J, Cosio B, et al. Network medicine analysis of COPD multimorbidities. Respir Res. 2014;15:111.

18. Yang W, Ni H, Wang H, Gu H. NLRP3 inflammasome is essential for the development of chronic obstructive pulmonary disease. Int J Clin Exp Pathol. 2015;8(10):13209-16.

19. Vandanmagsar B, Youm YH, Ravussin A, Galgani JE, Stadler K, Mynatt RL, et al. The NLRP3 inflammasome instigates obesity-induced inflammation and insulin resistance. Nat Med. 2011;17(2):179-88.

20. Mirrakhimov AE. Chronic obstructive pulmonary disease and glucose metabolism: a bitter sweet symphony. Cardiovasc Diabetol. 2012;11:132.

21. Kirkham PA, Barnes PJ. Oxidative stress in COPD. Chest. 2013;144(1):266-73.

22. Rains JL, Jain SK. Oxidative stress, insulin signaling, and diabetes. Free Radic Biol Med. 2011;50(5):567-75.

Page 12/14 
23. Cazzola M, Rogliani P, Calzetta L, Lauro D, Page C, Matera MG. Targeting Mechanisms Linking COPD to Type 2 Diabetes Mellitus. Trends Pharmacol Sci. 2017;38(10):940-51.

24. Rogliani P, Ora J, Di Daniele N, Lauro D. Pleiotropic effects of hypoglycemic agents: implications in asthma and COPD. Curr Opin Pharmacol. 2018;40:34-8.

25. Kothari V, Galdo JA, Mathews ST. Hypoglycemic agents and potential anti-inflammatory activity. J Inflamm Res. 2016;9:2738.

26. Consoli A, Formoso G. Do thiazolidinediones still have a role in treatment of type 2 diabetes mellitus? Diabetes Obes Metab. 2013;15(11):967-77.

27. Barnett $\mathrm{AH}$. Redefining the role of thiazolidinediones in the management of type 2 diabetes. Vasc Health Risk Manag. 2009;5(1):141-51.

28. Ialenti A, Grassia G, Di Meglio P, Maffia P, Di Rosa M, lanaro A. Mechanism of the anti-inflammatory effect of thiazolidinediones: relationship with the glucocorticoid pathway. Mol Pharmacol. 2005;67(5):1620-8.

29. Bhowmik A, Seemungal TA, Sapsford RJ, Wedzicha JA. Relation of sputum inflammatory markers to symptoms and lung function changes in COPD exacerbations. Thorax. 2000;55(2):114-20.

30. Donaldson GC, Seemungal TA, Patel IS, Bhowmik A, Wilkinson TM, Hurst JR, et al. Airway and systemic inflammation and decline in lung function in patients with COPD. Chest. 2005;128(4):1995-2004.

31. Perera WR, Hurst JR, Wilkinson TM, Sapsford RJ, Mullerova H, Donaldson GC, et al. Inflammatory changes, recovery and recurrence at COPD exacerbation. Eur Respir J. 2007;29(3):527-34.

32. Wedzicha JA, Seemungal TA, MacCallum PK, Paul EA, Donaldson GC, Bhowmik A, et al. Acute exacerbations of chronic obstructive pulmonary disease are accompanied by elevations of plasma fibrinogen and serum IL-6 levels. Thromb Haemost. 2000;84(2):210-5.

33. Chang $\mathrm{C}$, Yao W. Time course of inflammation resolution in patients with frequent exacerbations of chronic obstructive pulmonary disease. Med Sci Monit. 2014;20:311-20.

34. Choi J, Min, K.H., Chung, S., Oh, J.Y., Sim, J.K., Hur, G.Y. et al. Prevalence of bacterial and viral infections in acute exacerbation of chronic obstructive pulmonary disease in single center in South Korea. Am Thorac Soc 193, A5178. 2016.

35. Glass CK, Saijo K. Nuclear receptor transrepression pathways that regulate inflammation in macrophages and T cells. Nat Rev Immunol. 2010;10(5):365-76.

36. Law RE, Goetze S, Xi XP, Jackson S, Kawano Y, Demer L, et al. Expression and function of PPARgamma in rat and human vascular smooth muscle cells. Circulation. 2000;101(11):1311-8.

37. Sugawara A, Takeuchi K, Uruno A, Ikeda Y, Arima S, Kudo M, et al. Transcriptional suppression of type 1 angiotensin II receptor gene expression by peroxisome proliferator-activated receptor-gamma in vascular smooth muscle cells. Endocrinology. 2001;142(7):3125-34.

38. Mannucci E, Monami M, Lamanna C, Gensini GF, Marchionni N. Pioglitazone and cardiovascular risk. A comprehensive metaanalysis of randomized clinical trials. Diabetes Obes Metab. 2008;10(12):1221-38.

39. Selvin E, Bolen S, Yeh HC, Wiley C, Wilson LM, Marinopoulos SS, et al. Cardiovascular outcomes in trials of oral diabetes medications: a systematic review. Arch Intern Med. 2008;168(19):2070-80.

\section{Figures}




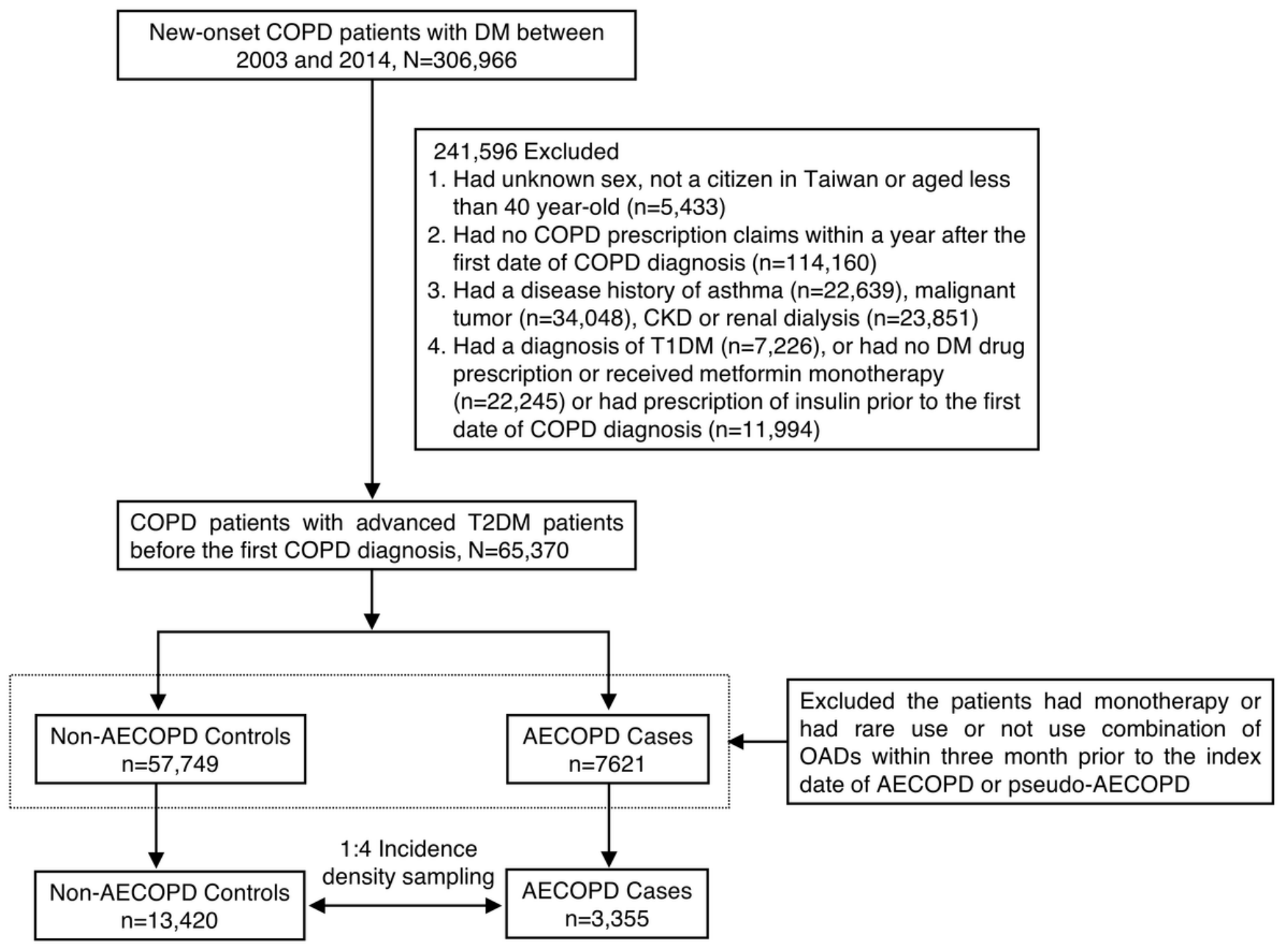

Figure 1

Figure 1

Patient selection process Abbreviation: AECOPD, acute exacerbations chronic obstructive pulmonary disease; CKD, chronic kidney disease; COPD, chronic obstructive pulmonary disease; DM, diabetes mellitus; OADs, oral antihyperglycemic drugs; T1DM, type 1 diabetes mellitus; T2DM, type 2 diabetes mellitus 